\title{
Designing Control Points in UAV-Photogrammetry Mapping Using GNSS Concept to Produce Land Use Map (Case Study: Ciwidey Village, Bandung Regency, Indonesia)
}

\author{
Sadikin Hendriatiningsih, Asep Y. Saptari, Sudarman, Ratri Widyastuti, Putri Rahmadani
}

Surveying and Cadastre Research Division, Institut Teknologi Bandung, 40132, Indonesia

\begin{abstract}
Production of orhtophoto maps from UAV-photogrammetry method depend on aerial data and control points that are measured by GNSS method. Quality control of orhtophoto maps need comparison coordinate from Check Points and orthophoto maps coordinate to calculate the Root Mean Square Error (RMSE). So that, quality of control points is important in aerial data processing. In this research, baseline length, observation time, measurement method, and area characteristics will be discussed based on the GNSS concept to fulfill the accuracy standard of control points from the American Society of Photogrammetry and Remote Sensing (ASPRS). The shorter baseline length, and the loner observation time, accuracy should be increase significantly, but it depends on the field situation and the accuracy required for the user. After all, the result of this research is to obtain control points design based on GNSS concept in Ciwidey Village, Bandung Regency
\end{abstract}

\section{Introduction}

Unmanned Aerial Vehicle (UAV) - Photogrammetry mapping can be used for many applications, for example to produce base map in high resolution that can be used in many purposes, such as land use map. Standard accuracy refer to the standard accuracy by American Society of Photogrammetry and Remote Sensing.

UAV-photogrammetry processing need control points where distribute evenly in the Area of Interest (AOI). One way to produce high accuracy of control points is using GNSS method. The concept of GNSS is used to determine the position of a receiver on land, at sea, or in space by means of constellation of multiple artificial satellites [1]. GNSS use many satellite such as GPS, GLONAS, GALILEO, SBAS, QZSS, and BEIDOU. These kind of GNSS satellite can be used in many applications. There are five stages of basic GNSS concept; firstly, GNSS satellites orbit the earth; secondly, GNSS regularly broadcast their ephemerides, time, and their status; thirdly, GNSS user equipment receives the signals from multiple GNSS satellites, receive information the time it takes the signals to travel from the satellite to the receiver; fourthly, GNSS user equipment uses the recovered information to compute time and position; fifthly, GNSS user equipment utilizes the position and time information in their applications [2]. Positioning with wide-area GNSS network is basically based on Differential Global Positioning System (DGPS) and Real Time Kinematic (RTK) concept [3]. It is a method to define unknown position by knowing the distance from three known points [2].

Device that uses GNSS concept is Global Positioning System (GPS) receiver. A typical non-geodetic grade GPS can estimate the user's position accuracy about 12 meters, but GPS-geodetic-grade can produce position that are accurate to sub-centimeter level [3]. Therefore, device selection in data acquisition stage must be adjusted to the research purposes. Furthermore, there are various satellite observation methods that will affect the data accuracy. This research discuss how to manage data acquisition using GNSS concept in order to fulfill required accuracy of control point.

\section{Methodology}

The purpose of this research is to obtain control points in certain accuracy to produce high accuracy of orhtophoto maps. Methodology of this research can be seen in Figure 1.

\footnotetext{
*Corresponding author: hningsih@gmail.com
} 


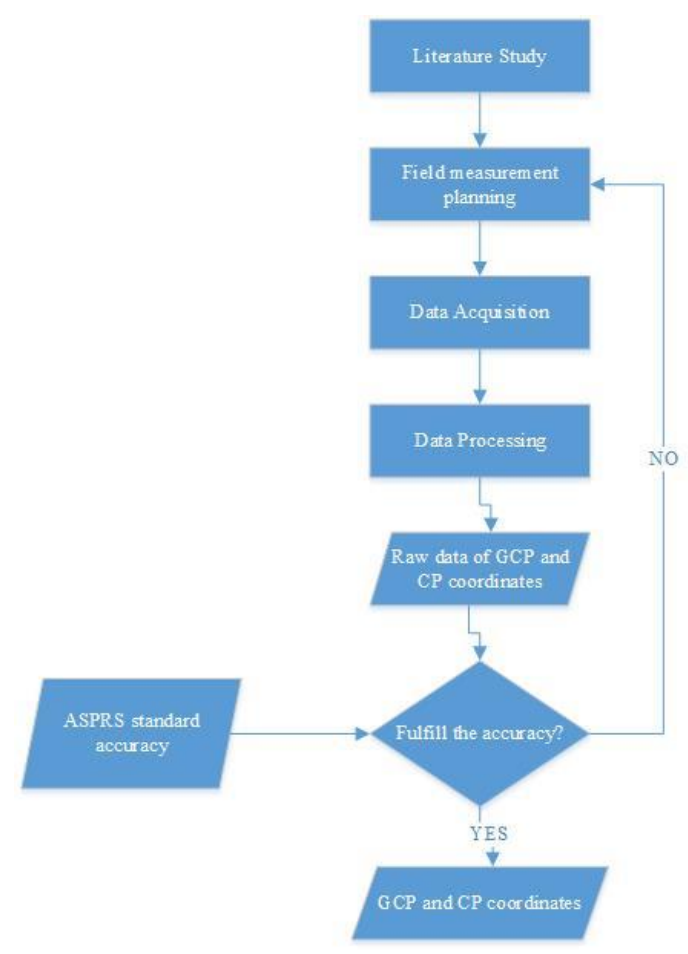

Figure 1. Methodology scheme

Figure 1 can be explained as follows:

\subsection{Literature Study}

There are some errors in GNSS that affect accuracy, including clock-related errors, signal propagation errors, system errors, intentional error sources, user equivalent error, and dilution of precision [4].

GPS positional accuracy can be improved by using differential correction obtained by using a technique called Differential GPS (DGPS), which has been known to provide the most accurate positioning result [5]. Differential GPS concept need two receivers: one is referred to the base station (known coordinates point) and the other one is referred to the rover (unknown point), so that the common errors such as clock synchronization errors and the atmospheric range delays can be eliminated by differential method observation [3]. There are estimated of DGPS positioning accuracy in the equation below [3]:

DGPS-A $= \pm[0.5 \mathrm{~cm}+1 \mathrm{ppm}$ of $\mathrm{BL}$

where:

\section{DGPS-A: DGPS positioning accuracy}

$\mathrm{BL}$ : baseline length

Satellite observation methods also affect the control point's accuracy. There are several methods of satellite observation, rapid static, stop and go, pseudo-kinematic, and combination methods [6]. Generally, rapid static method uses in radial mode and vulnerable to the effects of errors and bias. Stop-and-go method must be based on differential positioning methods using phase data and the determination of the correct phase ambiguity is essential from this method. As in the case of rapid static methods, this pseudo-kinematic method requires a good satellite geometry, a low level of bias and error in the data, and a relative environment that does not cause multipath effects. Basically, the selection of satellite observation methods affects the length of time observation in the field. Moreover, length of time observation and open space observation location is affected the accuracy [6].

\subsection{Field Measurement Planning}

There are some parameters that need to be considered to do a GPS survey, described as follows [6]:

\section{a. equipment}

The type of GPS receiver that would be used in field survey has to be planned first. Equipment selection affects the accuracy produced during the survey.

\section{b. observation strategy}

Things that are taken into consideration for the GPS observation strategy are observation methods, time and duration of observation, reference points, and observation of quality control. There are two kind of observation methods such as post processing method and real-time method. Static, rapid static, stop-and-go, pseudokinematic, and kinematic methods are included in post processing observation methods. Prolonged observation can lead to better randomization of the effects of orbital errors and the biased effects of the ionosphere and troposphere on distance measurement data [7]. Furthermore, number of satellite, satellite type, ionosphere activity, signal obstruction, receiver type (single or dual frequency), and point's accessibility must be considered to determine the length of time of observation. The reference point is used to bind unknown points that are measured to define the datum from the corresponding basic framework.

c. implementation mechanism

Number of personnel, job desk distribution, communication and transportation, equipment, and accommodation need to be prepared before field survey.

\section{d. observation geometry}

Condition of device location need to be considered. to avoid multipath effect and noise effect, device location need to be far away from reflective objects and elevation mask ranges from $10^{0}-15^{0}$. Furthermore, other condition must be considered such as the location is easy to reach, safe and has a stable soil structure. 
e. data processing strategy

There are several prominent characteristic for GPS data processing, such as [8]:

- $\quad$ point coordinates are determined in three dimensions towards a geocentric Cartesian coordinate system defined by the 1984 WGS datum

- the estimation process of baseline vector and point coordinates refer on the least squares method

- Data processing is processed after data from several GPS receivers involved are collected

- Data processing is processed in stages, from the baseline to the baseline so that it forms a network, which is then followed by network alignment and coordinate transformation from the 1984 WGS datum to the datum used by the user

Regarding to the Standard Accuracy by American Society of Photogrammetry and Remote Sensing, horizontal accuracy standards for digital planimetric data class I = $1.25 \%$ of map scale factor. This research was planning to produce 1:5000 scale maps of landuse map. So, this research need to produce $0.625 \mathrm{~mm}$ horizontal accuracy of orhtophoto map, with the assumption to produce required orhtophoto map, horizontal accuracy for control points are 0.5 of required orhtophoto map. So that the horizontal accuracy of the control points is less than $0.325 \mathrm{~m}$. Referred to the equation (1), maximum value of baseline length is $\pm 32 \mathrm{~km}$. Furthermore, some parameters as explained above need to be considered.

\subsection{Data Acquisition}

Table 1 describe data acquisition in this research.

Table 1. Data Acquisition Information

\begin{tabular}{|c|c|}
\hline Type & Information \\
\hline Equipment & $\begin{array}{l}\text { GPS Emlid Reach Rs, single } \\
\text { frequency, }\end{array}$ \\
\hline Observation Methods & $\begin{array}{l}\text { Real Time Kinematic } \\
\text { Methods for Control Point } \\
\text { and Rapid Static methods for } \\
\text { Check Point }\end{array}$ \\
\hline Number of GPS & 3 Receiver \\
\hline Number of Personnel & 4 persons \\
\hline Mask Elevation & $10^{0}$ \\
\hline Baseline Length & $<25$ kilometers \\
\hline $\begin{array}{l}\text { Time Duration of field } \\
\text { survey }\end{array}$ & 10 days \\
\hline
\end{tabular}

GPS device have been using in this research is GPS geodetic but using one single frequency. Number of control pints is 11 points. Because there are none reference point near Ciwidey, so one base point in Ciwidey area is being taken from Indonesian Geospatial Information Agency (BIG) benchmark in Padalarang area for four hours observation used static methods. Ten GCP observed for \pm 0.5 hour for each control point used Real Time Kinematic (RTK) method. Furthermore, 20 check points observation used static method is also conducted along with check point observation. Check point and control point observation need 10 days because of rain makes the work takes much longer than it should. Satellite observation methods are chosen based on the accuracy requirements and time available to conduct field surveys

Job desk distribution is for four persons, one person is a driver, and the other did the observation. Baseline distance from BIG benchmark as referenced point to base point in Ciwidey is $\pm 28 \mathrm{~km}$.

Control point distribution can be seen in Figure 2 and check point distribution can be seen in Figure 3.

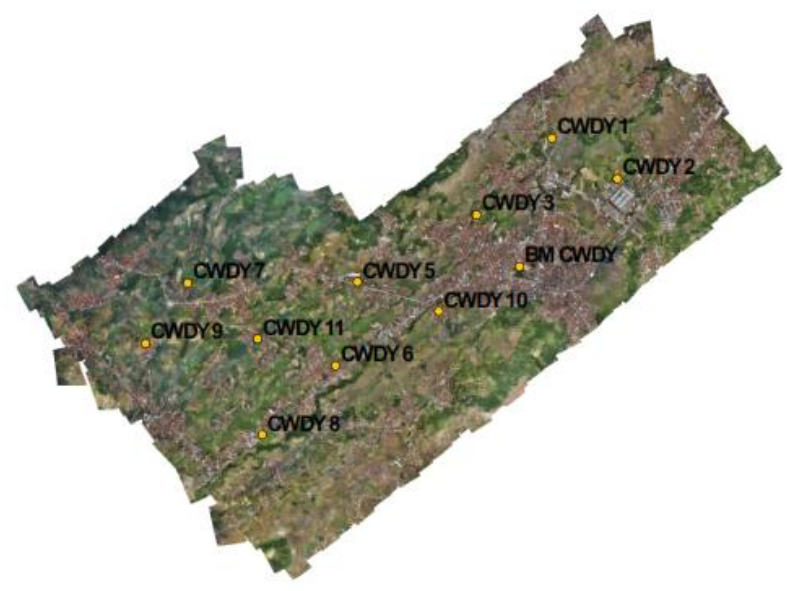

Figure 2. Control Point Distribution

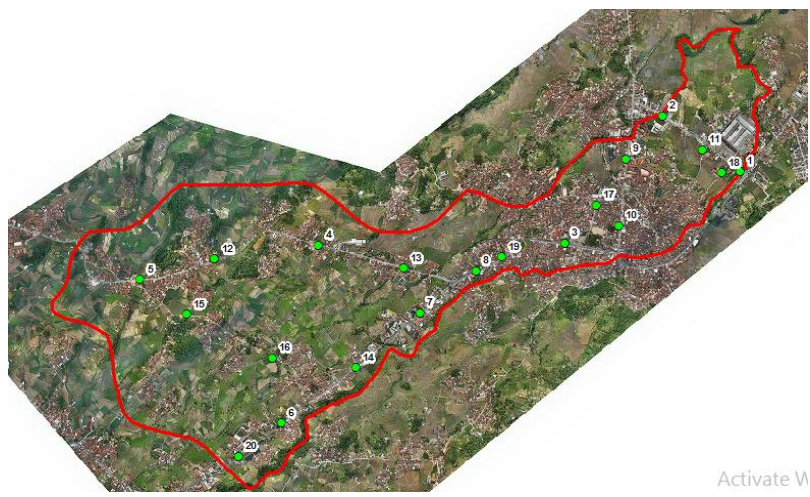

Figure 3. Check Point Distribution

\subsection{Data Processing}

RINEX format is received from the GPS device. Data processing in this research using open source software, RTK Lib. Because this is open source software and can processed many varies of GPS devices, there are some parameters must be defined first, such as antenna height, 
and approximate station coordinates. The concept of data processing can be seen in Figure 4.

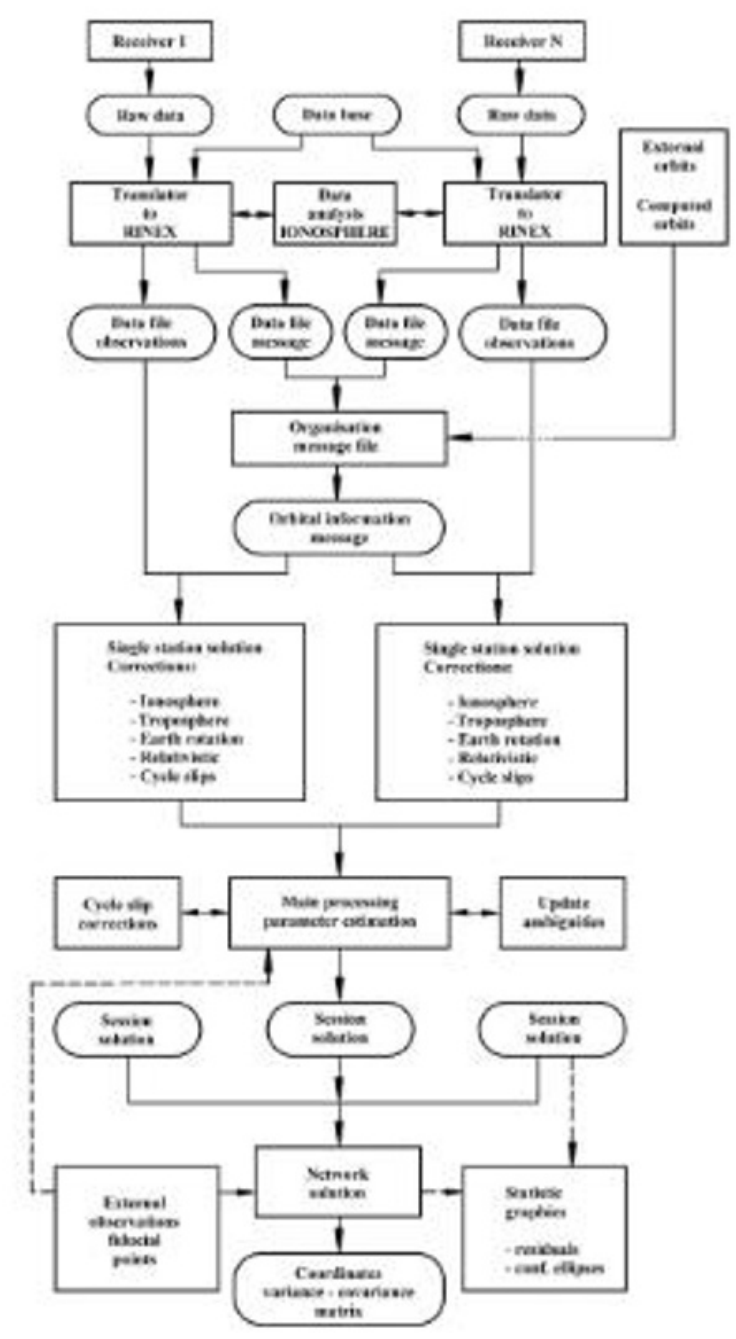

Figure 4. Simplified functional flow diagram of generic GPS software package [9]

\section{Result And Discussion}

Referred to equation (1) about DGPS positioning accuracy, Table 2 is a comparison between equations (1) based in the baseline length and horizontal accuracy calculation based on the observation data.

Table 2. Comparison DGPS positioning accuracy prediction and horizontal accuracy of data processing

\begin{tabular}{lcc}
\hline $\begin{array}{c}\text { Control } \\
\text { Point }\end{array}$ & $\begin{array}{c}\text { Horizontal } \\
\text { accuracy } \\
(\mathbf{m})\end{array}$ & $\begin{array}{c}\text { DGPS- } \\
\text { A (m) }\end{array}$ \\
\hline BM CWDY & 0.001 & 0.035 \\
CWDY 1 & 0.004 & 0.006 \\
CWDY 2 & 0.003 & 0.006 \\
CWDY 3 & 0.004 & 0.005
\end{tabular}

\begin{tabular}{ccc}
\hline $\begin{array}{c}\text { Control } \\
\text { Point }\end{array}$ & $\begin{array}{c}\text { Horizontal } \\
\text { accuracy } \\
\text { (m) }\end{array}$ & $\begin{array}{c}\text { DGPS- } \\
\text { A (m) }\end{array}$ \\
\hline CWDY 5 & 0.004 & 0.006 \\
CWDY 6 & 0.001 & 0.006 \\
CWDY 7 & 0.006 & 0.007 \\
CWDY 8 & 0.003 & 0.007 \\
CWDY 9 & 0.006 & 0.008 \\
CWDY 10 & 0.001 & 0.006 \\
CWDY 11 & 0.003 & 0.007 \\
\hline
\end{tabular}

Table 2 indicate that the result of horizontal accuracy of this research below from the horizontal accuracy prediction from equation (1). So that, the equation (1) can be applied to plan the control points distribution based on the baseline length.

As mentioned in the sub-section 2.1, there are various variable that affect accuracy. Table 3 gives the information about horizontal accuracy, baseline length, and radius of open space.

Table 3. Control Point's information

\begin{tabular}{ccccc}
\hline Control & $\begin{array}{c}\text { Horizontal } \\
\text { Point } \\
\text { Standard } \\
\text { Deviation } \\
(\mathbf{m})\end{array}$ & $\begin{array}{c}\text { Baseline } \\
\text { Length } \\
(\mathbf{m})\end{array}$ & $\begin{array}{c}\text { Time } \\
\text { Duration } \\
(\text { minute) }\end{array}$ & $\begin{array}{c}\text { Radius } \\
\text { of Open } \\
\text { Space } \\
(\mathbf{m})\end{array}$ \\
\hline CWDY 1 & 0.004 & 917.751 & 28.700 & 5.319 \\
CWDY 2 & 0.003 & 911.474 & 43.733 & 10.893 \\
CWDY 3 & 0.004 & 464.828 & 31.017 & 11.745 \\
CWDY 5 & 0.004 & 1127.773 & 40.033 & 5.316 \\
CWDY 6 & 0.001 & 1447.740 & 86.533 & 28.707 \\
CWDY 7 & 0.006 & 2301.420 & 64.083 & 15.254 \\
CWDY 8 & 0.003 & 2129.266 & 80.667 & 1.630 \\
CWDY 9 & 0.006 & 2645.321 & 35.200 & 2.977 \\
CWDY 10 & 0.001 & 639.555 & 60.500 & 8.844 \\
CWDY 11 & 0.003 & 1882.338 & 94.150 & 2.257 \\
\hline \multicolumn{5}{c}{ : Highest value } \\
: Lowest value & & \\
\end{tabular}

Point 'CWDY 9' gives highest value of horizontal standard deviation and baseline length. It indicates that baseline length affect the horizontal accuracy in that point. Shorter baseline length increase horizontal accuracy. Point 'CWDY 6' gives the lowest value of horizontal standard deviation but gives the highest value in radius of open space. It indicates that longer radius of open space increase the horizontal accuracy. Conclusion of Table 3, indicates that the open space radius, baseline length, and duration of observation influence each other on horizontal accuracy as mentioned in the concept of satellite observation

\section{Conclusion}


Equation (1), prediction of horizontal accuracy can be applied to design the control point distribution for the benefit of orhtophoto processing. Location selection of control points must consider baseline length, time duration of satellite observation, radius of open space, accuracy requirements, time schedule of field survey, number of human resources, and device availability. The methodology of this research can be applied to obtain control points in UAV-Photogrammetry method.

\section{Reference}

[1] S. Dawoud, "GNSS principles and comparison," Postdam University.

[2] C. Jeffrey, An Introduction to GNSS, Canada: NovAtel Inc, 2010.

[3] T. A. Ali, "Positioning with Wide-Area GNSS Networks: Concept and Application," Positioning, pp. 1-6, 2012.

[4] M. Karaim, M. Elsheikh and A. Noureldin, "GNSS Error Sources," in Multifuntional Operation and Application of GPS, Intechopen, 2018.

[5] P. V. Bolstad, J. Andy and B. Jon, "A Comparison of Autonomous, WAAS, Real-Time, and PostProcessed Global Positioning Systems (GPS) Accuracies in Northern Forests," Northern Journal of Applied Forestry, pp. 5-11, 2005.

[6] H. Z. Abidin, Survei Dengan GPS, Bandung: Penerbit ITB, 2011.

[7] D. Wells, N. Beck, D. Delikaraoglou, A. Kleusberg, E. J. Krakiwsky, G. Lachapelle, R. B. Langley, M. Nakiboglu, K.-P. Schwarz, J. M. Tranquilla and P. Vanicek, "Guide to GPS Positioning," Geodesy and Geomatic Engineering UNB, Canada, 1999.

[8] R. C. Principles and Practice of GPS Surveying, School of Geomatic Engineering, University of New South Wales, 1997.

[9] G. Seeber, Satellite Geodesy, Berlin: Walter de Gruyter, 2003. 